José María Nieva

Profesor en la Universidad del Norte Santo Tomás de Aquino

Argentina

\title{
Ejercicios espirituales y trascendencia en Dionisio Areopagita
}

La figura de Dionisio Areopagita es enigmática desde su origen y este enigma se ha acrecentado con el paso del tiempo. Situado hacia finales de la antigüedad tardía, convergen en su obra las grandes corrientes de la filosofía griega, especialmente el neoplatonismo tardío de Jámblico y Proclo, y el cristianismo, "asumido" en el nombre del convertido por san Pablo en el Areópago según la narración de los Hechos de los Apóstoles 17,34.

Esa extraña simbiosis entre filosofía neoplatónica y cristianismo hace al PseudoDioniso Areopagita escapar a toda categorización clara y distinta en una línea de pensamiento; puntos no muy claros en su obra, como por ejemplo, la cristología y, por otro lado, la dependencia literal respecto de Proclo en núcleos temáticos como el tópico del mal en De Divinis Nominibus IV, hacen a los intérpretes del Corpus Dionysiacum plantear graves interrogantes: ¿helenización del cristianismo o un cristianismo desvirtuado en aras de exponerlo ante la filosofía neoplatónica, la gran corriente del siglo V? (1).

No pretendemos zanjar esta cuestión crucial para la comprensión de la obra dionisiana, sino interrogarnos respecto de un texto particular, puesto que "hacia el fin del siglo $\mathrm{V}$ un grupo de escritos, que su autor anónimo pone bajo el patronazgo de Dionisio Areopagita, expone con nuevos detalles, particularmente en la obra titulada Teología Mística, la vía apofática de acceso al principio de todas las cosas" (2).

A este respecto, las preguntas que dan razón de nuestra comunicación podrían formularse del siguiente modo: ¿cuáles son los ejercicios espirituales que subyacen en el texto dionisiano y qué sentido tienen en el horizonte total del mismo?, ¿adónde conduce la realización de estos ejercicios? En otras palabras, ¿cuál es el camino que debe realizar el espíritu para acceder al Principio de todas las cosas?

(1) Cfr. W. Beierwaltes, Platonismo nello cristianesimo, Milán, Vita e Pensiero, 2000; E. von Ivánka, Plato Christianus. La réception critique du platonisme chez les Péres de l'Église, Paris, PUF, 1990; R. Roques, L’Univers Dionysien, Paris, Cerf, 1983 y Strucutres Théologiques. De la gnose á Richard du Saint-Victor, Paris, PUF,1962; I. Sheldon-Williams, "The Greek Christian Platonist Tradition from The Cappadocians to Maximus and Eriugena" en A. Armstrong, The Cambridge History of Later Greek and Early Medieval Philosophy, Cambridge, 1967.

(2) P. Hadot, Exercicies Spirituels et philosophie antique, Paris, Études Augustiniennes, 1981, p. 190. Seguimos a este autor en la noción de "ejercicios espirituales" que como se verá son esfuerzos de reflexión que envuelven a todo el sujeto. 
En la búsqueda de responder a estos interrogantes, recurriremos a los tres parágrafos que componen el capítulo uno de su obra De Mystica Theologia.

\section{EJERCICIOS ESPIRITUALES}

El Areopagita comienza su breve y, en cierto sentido, oscuro tratado con una oración a la Trinidad, la cual es nombrada a través de una triple adjetivación superlativa.

En efecto, la Trinidad es "supraesencial, supradivina y suprabuena" (MT 1, 1,997 a).

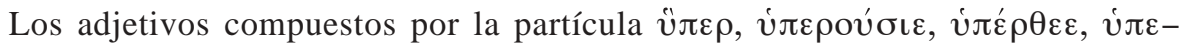
$\rho \alpha ́ \gamma \alpha \theta \varepsilon \varepsilon$, que denotan lo que se encuentra más allá sobrepasando a todo en dignidad y poder, lo absoluto sobre todas las cosas, pueden ya darnos alguna pista de cuál es el camino que el espíritu debe seguir para poder alcanzar "la más alta cima más que incognoscible y más que luminosa de los Oráculos místicos, allí donde los misterios simples, absolutos e inmutables de la teología han sido envueltos en la Tiniebla más que luminosa del silencio iniciador del secreto, haciendo resplandecer en la oscuri-

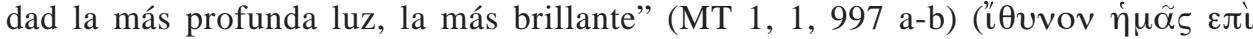

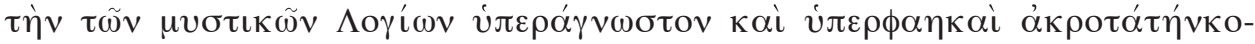

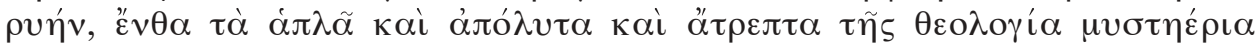

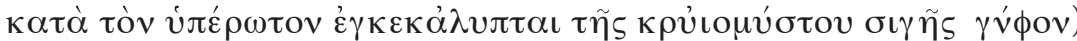

La oración de Dionisio continúa con una recomendación a Timoteo que, según nuestro entender, pone más en claro la marcha a realizar para acceder al Principio de todas las cosas, es decir, los pasos a seguir para la unión con Dios: "Y tú, querido Timoteo, ejercítate intensamente en las contemplaciones místicas, abandona las sensaciones y las actividades intelectuales, todo lo sensible y lo inteligible, todo lo que es y todo lo que no es, y elévate, tanto como es posible, por vía de no-conocimiento, a la unión con Aquel que trasciende toda esencia y conocimiento" (MT 997b-1000

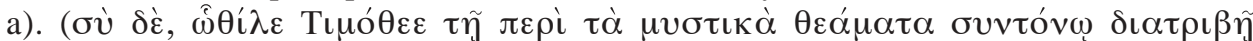

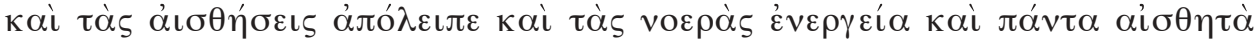

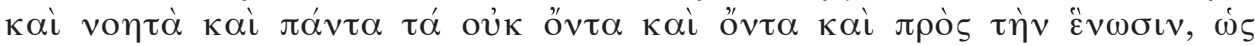

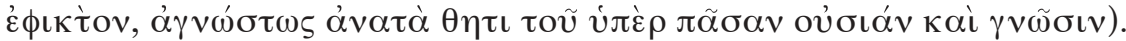

La recomendación a Timoteo, por lo tanto, radica en la realización de ejercicios espirituales, en largos esfuerzos de reflexión, en un movimiento global de la inteligencia en el cual confluyen, aunque con desigual fuerza de intensidad, lo sensible y lo inteligible; podemos decir que dichos ejercicios consisten en el abandono de las sensaciones y de las actividades intelectuales, es decir, de todo aquello que hace al conocimiento ordinario y común; es la supresión de la actitud natural del espíritu o de la inteligencia en su modo de conocer.

Un hecho significativo para marcar es que en todos estos ejercicios espirituales no se comienza por una purificación. En la tradición patrística del Oriente, el primer momento es este. Herencia de la catarsis platónica, se vuelve lucha contra las pasiones y adquisición de las virtudes morales que ponen en tensión hacia la perfección, lo que implica una concepción dinámica de la vida del espíritu.

Aquí no se encuentra la exigencia de una perfección moral, sino que el autor impone el abandono de todo conocimiento que pueda adquirirse a través de los sentidos y de la 
inteligencia en su operar discursivo, signo de multiplicidad, a aquel que desea ejercitarse en las contemplaciones místicas, es decir, en la visión de las verdaderas realidades.

Este abandono o renuncia en cuanto ejercicio espiritual está focalizado en el nivel de la actividad intelectual, en su discurrir espacio-temporal al forjar símbolos sensibles y conceptos que pretender atrapar al Uno supraesencial.

¿No subyace en todo esto la búsqueda de la unificación de sí de la inteligencia, es decir, la supresión de la discursividad, de lo múltiple, tópico tan querido para el neoplatonismo? ¿No repercute el imperativo plotiniano de "abandona todo" de Enneada V, 3 (49) 17, 38, que es huida de la multiplicidad y conquista de un estado de pureza noética que abre a la presencia de lo Uno? ¿No es el retorno o conversión que debe ir dejando de lado todo lo que la procesión efusivamente ha hecho ser?

Ahora bien, esta necesidad de abandonar todo, de suprimir todo se realiza por el doble movimiento de negación de lo sensible y de lo inteligible. La negación de ambos órdenes del conocimiento en cuanto ejercicio del pensamiento postula un verdadero movimiento anagógico del espíritu hacia la unión con Dios, es decir, la unificación de la inteligencia es una divinización progresiva para acceder a la verdadera contemplación. Este movimiento ascendente, anagógico, que es pura dinamicidad, delata que la actitud de Timoteo en este proceso debe ser más bien activa que pasiva; la inteligencia ha de purificar lo sensible y lo inteligible para luego rechazarlo y, podemos decir, que en este mismo proceso ella, paradojicamente, se purifica; sin embargo, como lo habíamos hecho notar, no es una purificación moral, la adquisición de determinadas virtudes que ponen en camino hacia la perfección. En este sentido, es significativo resaltar la estrecha vinculación que en el pensamiento de Dionisio Areopagita existe entre conocimiento y perfección. ¿No cabe recordar aquí la siempre presente exhortación neoplatónica de la asimilación, la semejanza con Dios?

Pero ¿por qué Dionisio impera a abandonar todo?; ¿qué otro sentido subyace en esta recomendación al destinatario de la obra?

La cesación de las dos actividades del espíritu humano, aquella de los sentidos y de la inteligencia, se explicita mejor al tener en cuenta que la misma imagen aparece en el parágrafo dos aunque de otro modo.

En efecto, en este parágrafo Dionisio censura la actitud de aquellos que, en su conocimiento de Dios, proceden por la vía de los sentidos y de la inteligencia, que se encuentran en la situación de profanos o de no iniciados, adjudicando a Dios atributos tomados del orden sensible e inteligible.

Lo que plantea en el fondo la gran pregunta: ¿la teología mística no es una verdadera iniciación en el misterio? o, con otras palabras, ¿no presenta el autor al cristianismo como una religión de misterios en la cual es necesario ser iniciado?, o al decir de García Bazán, ¿no se trata "de la tentativa de una comprensión metafísica del misterio cristiano y asimismo sensible al espíritu iniciático de sus rituales más antiguos?" (3); ¿no pide acaso el Areopagita poder alcanzar la cima de "los misterios absolutos, simples e inmutables de la teología?” (MT 1,1, 997 a) (4).

(3) F. García Bazán, "El Dios trascendente en Dionisio Areopagita. Neoplatonismo, gnosticismo y teúrgia" en EPIMELEIA. Revista de Estudios Sobre la Tradición, Año II- N4, (1993), p. 17.

(4) Cfr. Ysabel de Andía, Henosis. L'unión á Dieu chez Denys L'Areopagite, Leiden, Brill, 1996; E. von Ivánka, Plato Christianus, Paris, PUF, 1990. 
Esta distinción entre no-iniciados y profanos marca más claramente la finalidad de los ejercicios espirituales de abandono y negación, ya que "los no-iniciados están atrapados por los seres y se imaginan que no hay nada supraesencial más allá de los seres y creen conocer, con su propio conocimiento, a Aquel que hizo de la tiniebla su morada", mientras que los verdaderos profanos son "todos aquellos que, para definir la Causa trascendente de todas las cosas, la determinan por lo último de los seres y pretenden que la Causa no trasciende en nada las formas múltiples y profanas del mundo sensible que ellos se han forjado de ella" (MT 1, 2, 1000 a).

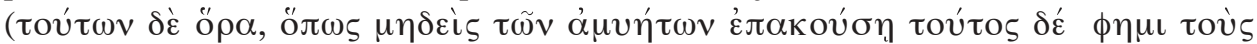

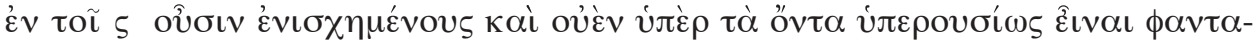

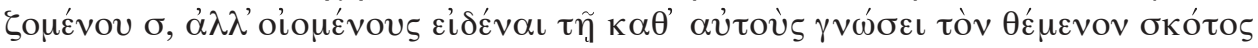

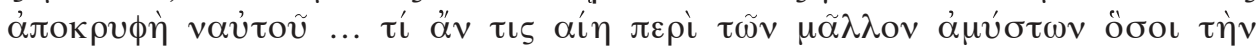

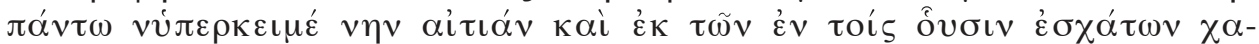

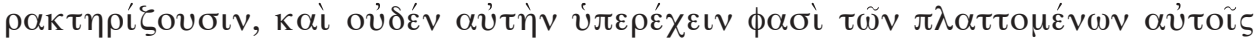

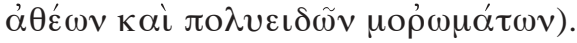

Esta clase de hombres se atienen solamente a las formas sensibles e inteligibles, es decir, a lo ordinario y común de la actividad de los sentidos y de la inteligencia. ¿No repercute aquí el pensamiento plotiniano que exige abandonar toda forma incluso inteligible puesto que lo Uno carece de forma al ser dador de toda forma?

Hay que dejar de lado todo ser, todo ente para poder conocer al Supraesencial. En esto consisten las "divinas iniciaciones, que escapan a los no-iniciados"(MT 1,2,

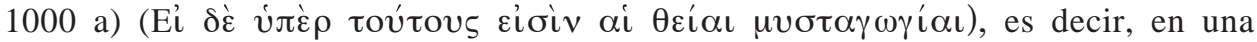
ascesis de la inteligencia o del espíritu en aras de abandonar todo nombre sensible e inteligible de la Causa buena de todas las cosas; por ello es que Dionisio puede afirmar a continuación: "Es necesario atribuir a la Causa y afirmar de ella todas las posiciones de los seres, porque Ella es causa de todo; y, de una manera más exacta,

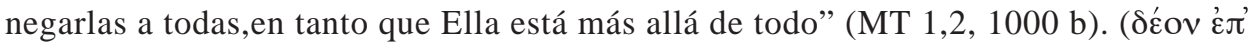

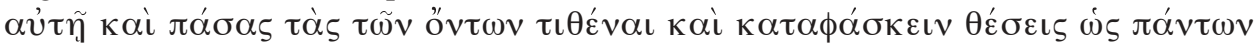

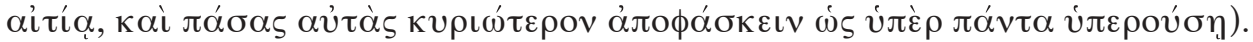

Puede comprenderse ahora el sentido que poseen estos ejercicio espirituales, es decir, el ejercicio del abandono y de la negación, de la apófasis que en cuanto tal es anagogía, elevación; estos ejercicios se llevan a cabo frente a las afirmaciones nominativas de Dios que hay que suprimir para, por este modo más exacto de conocer, hacer aparecer la Causa supraesencial de todo en su absoluta trascendencia.

En efecto, las negaciones no se oponen a las afirmaciones sino que la corrigen por un procedimiento más seguro, puesto que "no se debe creer que las negaciones se opongan a las afirmaciones sino que la Causa que está más allá de todo, está más

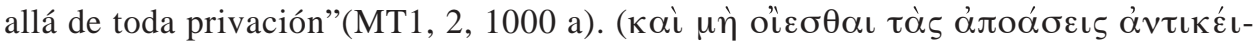

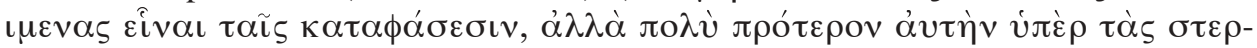

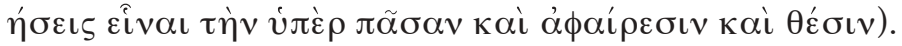

\section{EL SIMBOLISMO DE MOISÉS}

En el parágrafo tres de la obra que buscamos comprender, el Areopagita retoma, en una visión de conjunto, la marcha mística y la entrada en la Tiniebla. 
Apoya su interpretación de esta marcha en la autoridad y el ejemplo de Moisés; pero es una exégesis muy personal, ya que "las alusiones a la vida de Moisés son extremadamente sobrias respecto de los desarrollos que le han consagrado Filón de Alejandría y Gregorio de Nisa" (5). En esta exégesis puede apreciarse una clara tonalidad didáctica como también gnoseológica que puede aclararse con las siguientes explicaciones.

Podríamos resumir lo esencial de este parágrafo en una afirmación central: "La Causa buena de todas las cosas es sin palabras" (MT 1, 3, $1000 \mathrm{c})$. ( $\dot{\eta} \dot{\alpha} \gamma \alpha \theta \dot{\eta}$

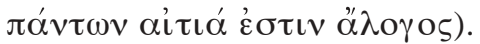

Al buscar dar razón de ella, Dionisio Areopagita parte de una observación del divino Bartolomé, sin duda haciendo alusión a las tradiciones apócrifas conocidas en la antigüedad cristiana bajo el nombre del apóstol. Ella marca el carácter a la vez extenso y breve de la teología, puesto que "respecto del Bien se pueden decir muchas cosas y que a la vez no se pueden decir grandes cosas e incluso no se puede decir nada, porque no hay de él ni palabra ni intelección, a causa de su trascedencia

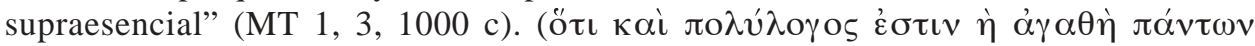

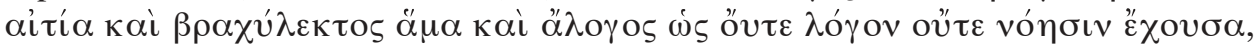

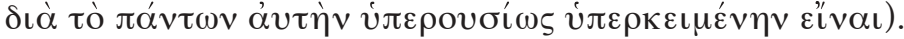

Esta afirmación retoma bajo otro ángulo el tema del abandono y formula la razón de ser de este abandono. El que busca conocer a Dios debe abandonar todo conocimiento que parte de los sentidos y de la inteligencia, ya que ellos llevan a la peligrosa pendiente del naturalismo y del antropomorfismo, dos formas no muy distintas de idolatría. De Dios no hay palabra ni intelección aunque es una Trascendencia absoluta. ¿No cabe recordar aquí la primera hipótesis del Parménides platónico que alude a lo Uno negativamente?

La inteligencia en su ejercicio afirmativo, en su discursividad, en su operar múltiple, no puede comprender a Aquel que está más allá de todo conocimiento. Por ello, era necesario proceder a un modo mejor de conocer qué es la negación. La apófasis, que es elevación en su ejercicio de corregir las afirmaciones, hace aparecer la trascendencia de Dios.

En este sentido el ejemplo de Moisés en su ascensión al Sinaí delata muy bien que la "ascensión mística es del orden del conocimiento" (6).

Dionisio la esboza a través de tres tiempos: Moisés debe llevar a cabo una purificación que, sin embargo, no es detalladamente explicada, pero que se deja percibir claramente en cuanto es un alejamiento de la muchedumbre, es decir, de la multiplicidad para unificarse; luego una superación de las cimas donde se encuentran las luces divinas, los sonidos y la palabras del cielo y, por último, la entrada en la Tiniebla "porque no es sin razón que el divino Moisés recibe la orden de purificarse primero, y luego, de separarse de aquellos que no son puros; y que después de una total purificación ... se separa de la muchedumbre, y llega, con los sacerdotes

(5) Cfr. R. Roques, Structures Théologiques, Paris, PUF, 1962, p.187 y H. C. Puech, En torno a la gnosis, Madrid, Taurus, 1976

(6) Ysabel de Andía, Henosis. L'union á Dieu chez Denys L'Areopagite, Leiden, Brill, 1996, p. 400. Cfr también E. Bellini, introducción a Dionigi Areopagita, Tutte Le Opere, Milán, Rusconi, 1991. 
elegidos, a la cima de las divinas ascensiones. Y luego Moisés se libera de todo objeto visto y de aquellos que lo ven y penetra en la Tiniebla verdaderamente misteriosa de la Incognoscibilidad, donde hace callar toda comprensión intelectual y llega a lo que es totalmente intocable e invisible" (MT 1, 3, 1001a).

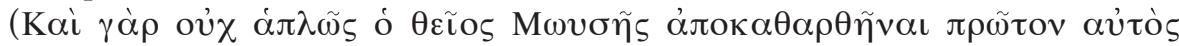

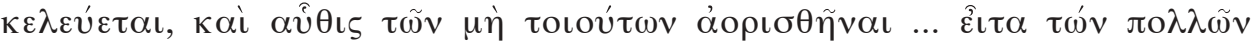

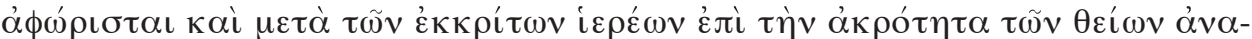

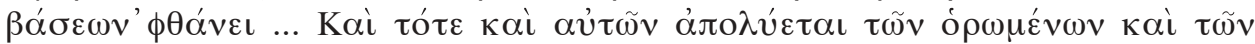

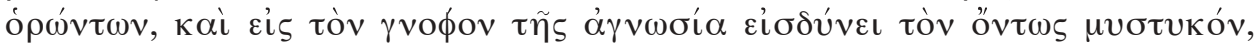

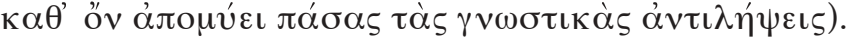

El abandono de todo hace lugar a la negación que revela un modo diferente de conocer, ya que la negación no debe ser entendida en un sentido privativo, sino en un sentido eminente o trascendente, es decir, es una negación trascendente, generadora de verdadero conocimiento; en ese sentido, podemos decir que da origen a un conocimiento místico y supraesencial a través del cual la inteligencia se eleva hacia Dios al despegarse de lo ajeno y tornarse simple. La realización de estos ejercicios espirituales, entonces, conduce cada vez más a una conciencia aguda de la trascendencia divina, de que Aquel que está más allá de todo escapa a toda palabra y a toda intelección.

Estos ejercicios espirituales no tienen otra finalidad que "la afirmación de una Trascendencia que escapa a todas las categorías humanas" (7), es decir, Dionisio concede a la Trascendencia un valor altamente positivo, su expresión más alta y válida.

La teología negativa que no debe ser comprendida, como esperamos haberlo mostrado, como una mera actividad negadora ejerce una función de purificación y de eliminación de todo antropomorfismo al cual pueden conducir las cualificaciones inteligibles de Dios.

En suma, la Trascendencia divina aparece como la razón de la realización de estos ejercicios espirituales que consisten en la obtención de un discurso negativo que sobrepasa lo sensible y lo inteligible; por ello el conocimiento místico, en cierto modo, es un no-conocimiento, es decir, conocer en el no-conocer.

La trascendencia de la Causa, que es fuente de todo y al mismo tiempo separada de todo es designada por las expresiones con modo eminente o trascendente de conocimiento como corresponde a la vía anagógica que busca alcanzar la divinización y la henosis del espíritu en la Tiniebla, dicho con otras palabras, el uso de la partícula hyper (ü $\varepsilon \varepsilon \rho)$ que se revela metódico en teología negativa tiene por fin o sentido resaltar, marcar la perfecta trascendencia

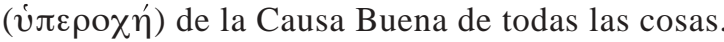

\section{A MODO DE CONCLUSIÓN}

Como habrá podido apreciarse, el apofatismo es una marcha del espíritu que apunta a una trascendencia a través de proposiciones o expresiones negativas, que

(7) R. Roques, op. cit., p. 160; D. Lang, "Le discours de la théologie face á l'indicible chez Denys L'Areopagite", Diotima 23, 1995; H.U. von Balthasar, Liturgie Cosmique, Paris, Aubier, 1947, p. 45; I. Sheldon-Williams, op. cit. 
en su construcción lingüística llevan ya toda la dinamicidad que el espíritu requiere para alcanzar su más alta realización, divinización y henosis.

En este sentido, sin duda, Dionisio Areopagita es heredero de la gran tradición platónica o, mejor dicho, neoplatónica, que en su singular exégesis del diálogo platónico Parménides elabora toda una teología a partir del proceso negativo que se lleva a cabo en la primera hipótesis, respecto de lo Uno. Llevada a su punto culmen por Plotino, para quien lo Uno no tiene forma ni siquiera inteligible, como se desprende de la enseñanza de Ennéada VI 9, 3, 36-45, y por lo tanto solo es aprehendido en un contacto místico inefable y esquematizada por Proclo en su Teología Platónica al mismo tiempo que eje vertebral, particularmente en el Comentario al Parménides, esta teología negativa revela los límites de la razón como así también del lenguaje en la búsqueda de acceder al Principio de todas las cosas.

Ahora bien, en Dionisio Areopagita este proceso anagógico-gnoseológico nos enfrenta con un gran tema y, a la vez, con un gran problema respecto de su propia obra: ¿teorización de la experiencia mística o transposición velada en elementos neoplatónicos de un suceso vivido cristianamente?

Responder esta pregunta exigiría desarrollar algunos puntos meramente esbozados en esta comunicación y que esperamos poder hacerlo en una obra mayor.

\section{RESUMEN}

La figura de Dionisio Areopagita es enigmática desde su origen y este enigma se ha acrecentado con el paso del tiempo.

En su obra convergen la filosofía neoplatónica y el cristianismo, dando origen a una extraña simbiosis que plantea a sus intérpretes graves interrogantes.

Este trabajo se propone indagar el camino apofático de acceso al Principio de todas las cosas. Para ello recurre a los tres primeros parágrafos del capítulo uno de De Mystica Teologia. Se pregunta cuáles son los ejercicios espirituales que subyacen en el texto y adónde conducen. Concluye mostrando que la finalidad de dichos ejercicios es la conciencia aguda de una Trascendencia que escapa a toda categorización humana.

\section{ABSTRACT}

There is an enigmatic image of Dyonisius Areopagite from his origin, and that enigma has become more profound with time.

In his work coalesce neo-platonic philosophy with Christianity and, as a result, there is a strange symbiosis which have produced unsolved questions by his interpreters.

This paper analyzs the negative path that leads to the Principle of all things. In order to accomplish this task, I will work with the first three paragraphs of the first chapter of De Mystica Theologia. I will consider the spiritual exercises that underlies in the text and where they point at. The paper concludes by showing that the purpose of those exercises is the sharp consciencie of a Trascendence that escapes all human categorization. 